\title{
Dynamics in the Deep Canada Basin, Arctic Ocean, Inferred by Thermistor Chain Time Series
}

\author{
M.-L. TIMMERMANS \\ Woods Hole Oceanographic Institution, Woods Hole, Massachusetts \\ H. MeLling \\ Fisheries and Oceans Canada, Institute of Ocean Sciences, Sidney, British Columbia, Canada \\ L. RAINVILLE \\ Woods Hole Oceanographic Institution, Woods Hole, Massachusetts
}

(Manuscript received 8 May 2006, in final form 20 July 2006)

\begin{abstract}
A 50-day time series of high-resolution temperature in the deepest layers of the Canada Basin in the Arctic Ocean indicates that the deep Canada Basin is a dynamically active environment, not the quiet, stable basin often assumed. Vertical motions at the near-inertial (tidal) frequency have amplitudes of 10$20 \mathrm{~m}$. These vertical displacements are surprisingly large considering the downward near-inertial internal wave energy flux typically observed in the Canada Basin. In addition to motion in the internal-wave frequency band, the measurements indicate distinctive subinertial temperature fluctuations, possibly due to intrusions of new water masses.
\end{abstract}

\section{Introduction}

Of the Arctic Ocean basins, the Canada Basin (Fig. 1), with a mean depth of about $3800 \mathrm{~m}$, has the largest volume and likely contains the oldest deep water. The Canada Basin has a thick (up to $1000 \mathrm{~m}$ ) well-mixed bottom layer, over top of which lies an approximately 300-m-thick temperature-salinity step structure (Figs. 2 and 3). The staircase structure, through which both the mean temperature and salinity increase with depth, is observed for about $1000 \mathrm{~km}$ across the entire basin and has been persistent for more than a decade. It is characterized by two to three mixed layers (10-60-m thick) separated by $2-16-m$-thick interfaces over which changes in potential temperature and salinity are only $\delta \theta \approx 0.003^{\circ} \mathrm{C}$ and $\delta S \approx 0.0007$, respectively (Timmermans et al. 2003).

The homogeneity of the bottom layer implies that convective mixing is occurring as a consequence of geo-

Corresponding author address: Mary-Louise Timmermans, WHOI, MS 21, Woods Hole, MA 02453.

E-mail: mtimmermans@whoi.edu thermal heating, and the staircase above is suggestive of double-diffusive convection. However, Timmermans et al. (2003) have shown that the staircase structure is likely maintained by a very weak heat flux and that most of the geothermal heat flux is escaping through basin boundary regions where there is evidence for enhanced mixing. Much is still unknown of this remarkable staircase, and the circulation in the deep Canada Basin. The existing spatially and temporally sporadic CTD profiles of the staircase structure and homogeneous bottom layer limit our ability to understand, for example, to what extent variations are spatial or temporal. Figure 2 shows potential temperature profiles of the deep water column throughout the Canada Basin taken during the 2002 CCGS Louis S. St-Laurent expedition. Significant spatial variations are observed; the potential temperature of the homogeneous bottom layer varies by more than $0.0025^{\circ} \mathrm{C}$ across the basin, and the depth of the top boundary of the homogeneous bottom layer varies by more than $200 \mathrm{~m}$.

Here, we present time series temperature measurements from a thermistor array deployed in 2002-03 in the Canada Basin (Fig. 1), and placed to span the tem-

DOI: $10.1175 / \mathrm{JPO} 3032.1$ 


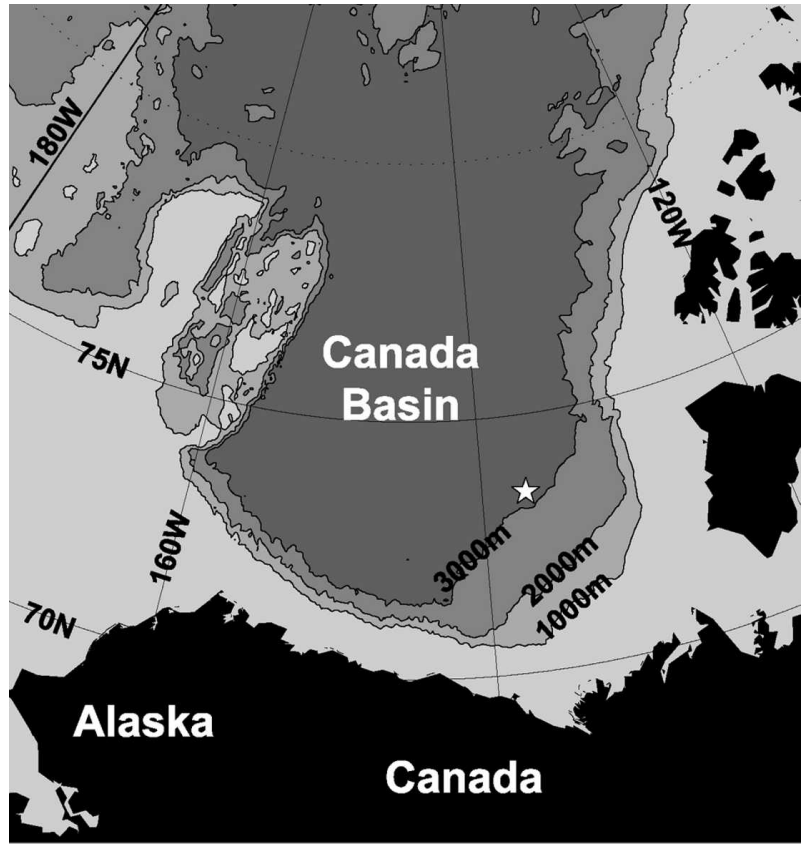

FIG. 1. The Canada Basin in the Arctic Ocean. The mooring location is marked by the star.

perature steps overlying the homogeneous bottom layer. Note that we can assume a tight temperaturesalinity relationship though the staircase and make inferences about its structure based on the temperature alone (see Timmermans et al. 2003). The mooring was designed to be a preliminary step toward observing and understanding the time variability and evolution of the staircase. The measurements, to our knowledge, make up the only deep temperature time series that exists for the remote and isolated Canada Basin.

In the next section, we present temperature time series and frequency spectra from the mooring array. Then in section 3, we first rule out the possibility of significant mooring motion at depth in the water column and discuss the temperature measurements in terms of both vertical and horizontal advection. As the results of our analysis indicate significant motion in the deep Canada Basin, we hypothesize as to the source. We summarize our results and emphasize the need for future field experiments in section 4 .

\section{Observations}

In 2002, we deployed a mooring in the Canada Basin at $73.5^{\circ} \mathrm{N}, 137^{\circ} \mathrm{W}$ (Fig. 1) in part to study the deep bottom layer and overlying staircase structure. Note that the mooring was called Pack Ice Thickness Station A (PITSA) because the shallow instruments measured thickness of drifting multiyear ice at a site referred to as

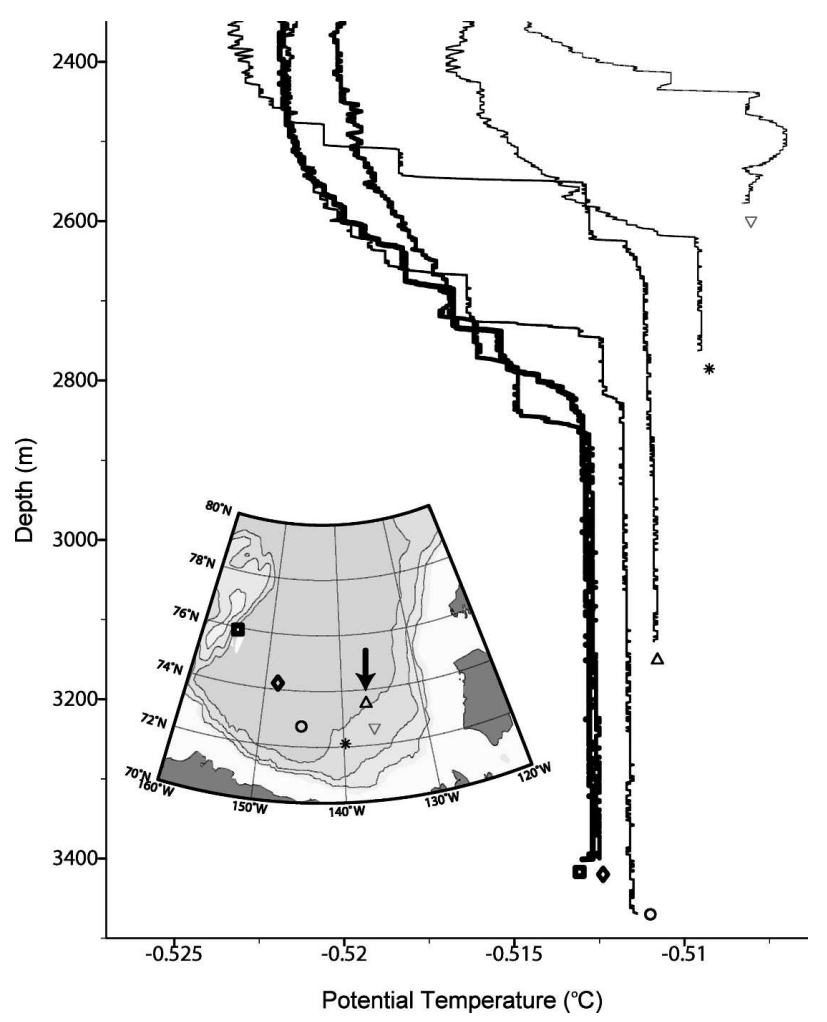

Fig. 2. Potential temperature $\left({ }^{\circ} \mathrm{C}\right)$ profiles in the Canada Basin in 2002. Data were collected from the Louis S. St-Laurent. An arrow points to the location of the mooring from which data are presented here.

Station A. The upper instruments on the mooring measured ice draft and velocity: An ice profiling sonar (IPS) was located about $46 \mathrm{~m}$ below the surface and an ADCP was located $50 \mathrm{~m}$ below the IPS.

The temperature array consisted of two self-contained temperature recorders [TR-1050 RBR Ltd (www. rbr-global.com)], as well as a self-contained data recorder (XR-420 RBR Ltd) operating with 16 thermistors placed in the configuration shown in Fig. 3. One TR-1050 unit was positioned to lie inside the homogeneous bottom layer, and the other was positioned to lie at the top of the staircase around the temperature minimum. The 150-m-long thermistor chain was centered vertically at a depth of $2517 \mathrm{~m}$, in between these two temperature units. The chain was configured such that the logging unit was at the mid depth, with thermistors 9 to 16 stretched vertically above it, such that thermistor 16 was the shallowest, and thermistors 8-1 (thermistor 7 failed at deployment) stretched below it, such that thermistor 1 was the deepest.

The mooring was deployed on 21 August 2002 (yearday 234). Temperature readings from the thermistors and TR-1050s were logged every $30 \mathrm{~min}$. We present measurements starting from 2000 UTC 22 August 2002 


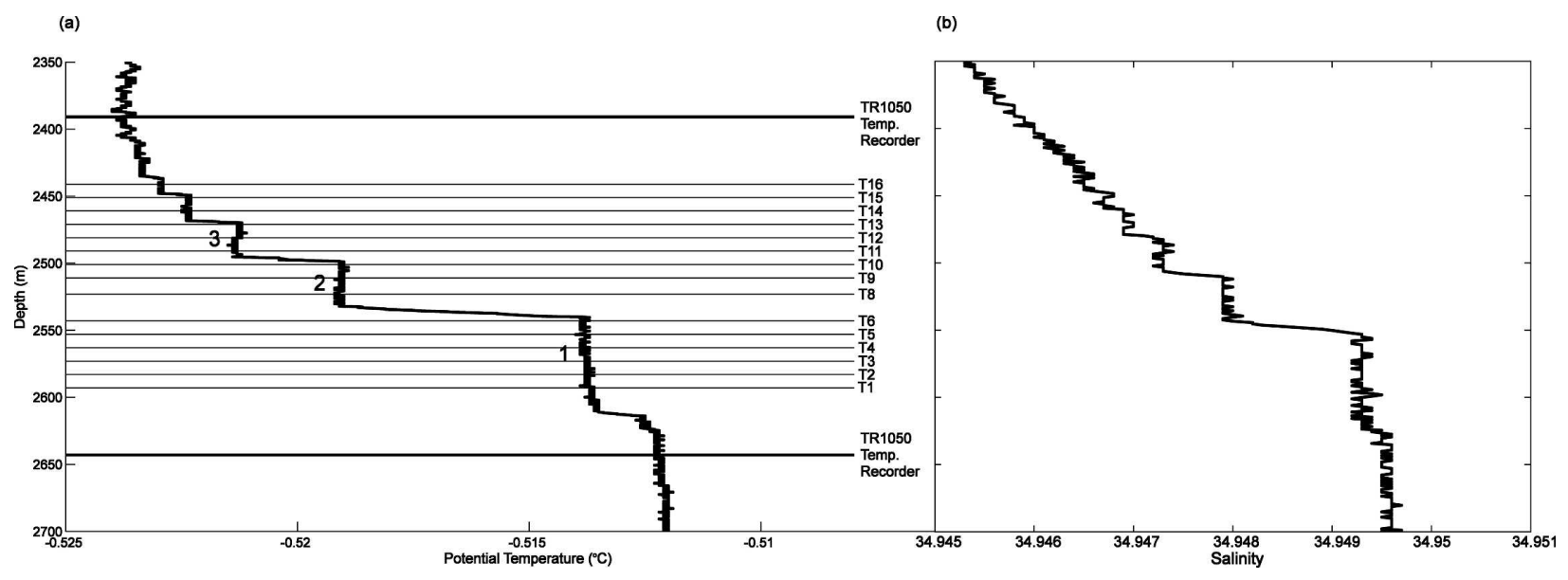

FIG. 3. Depths spanned by the temperature array in the water column. (a) Potential temperature and (b) salinity profiles were taken using an SBE911 CTD just prior to deployment of the mooring (21 Aug 2002). The three most prominent well-mixed layers are labeled 1-3 from deepest to shallowest.

as the first 100 records $(50 \mathrm{~h})$ after the deployment of the array were discounted to allow for stabilization of the instruments and mooring array in the water column (drifts in thermistor temperatures due to pressure creep were initially particularly large). The shallow TR-1050 logged until 26 November 2003 (461 days), while the deep TR-1050 failed on 15 April 2003 (after 236 days). Measurements from the thermistor chain were obtained until 12 October 2002 (51 days), after which time the chain failed because of a catastrophic leak.

The TR-1050s were calibrated to $\pm 0.001^{\circ} \mathrm{C}$, with instrument resolutions $\pm 0.0001^{\circ} \mathrm{C}$. Pre- and postdeployment calibrations were identical. Hence, it is reasonable to assume no drift in the TR-1050 measurements over the deployment.

The thermistors on the chain had no internal pressure housings under their outer polyurethane pods, which was unknown to us at the time of deployment. Hence, all of the thermistors on the chain were exposed to the full $2500-\mathrm{m}$ pressure and suffered severe and disparate pressure creep. Raw values were up to $0.5^{\circ} \mathrm{C}$ different from CTD measurements taken at the same depths at the mooring site. Further, temperatures from the thermistors did not lie in the range between temperature values from the TR-1050 units. Because the pressure stress on the thermistors was irreversible, we could only calibrate by using the deployment CTD temperature values at the known depths of the thermistors. This means that we were unable to measure gradual changes in the temperatures of the mixed layers in the staircase over time, only discrete steps in temperature could be measured. Thermistor resolutions were $\pm 0.0001^{\circ} \mathrm{C}$.

\section{a. TR1050 measurements}

Figure 4 shows the temperature record from both TR-1050 units. Linear fits are also shown, with slopes for both approximately $1 \times 10^{-6 \circ} \mathrm{C} \mathrm{m}^{-1}$, indicating no significant trends in temperature during the deployment (trends on the order of $0.001{ }^{\circ} \mathrm{C}$ over the time of measurement would be detectable).

We would expect an increase in temperature of the homogeneous bottom layer if it is convectively mixed by geothermal heat $\left(F_{H} \approx 50 \mathrm{~mW} \mathrm{~m}^{-2}\right)$ and if all of this heat remains in the layer. The potential temperature $\theta_{h}$ of this layer, of thickness $H \approx 580 \mathrm{~m}$ at the mooring site, evolves according to $d \theta_{h} / d t=F_{H} /\left(\rho c_{p} H\right)$, where $\rho=1040 \mathrm{~kg} \mathrm{~m}^{-3}$ is the density and $c_{p}=3900 \mathrm{~J} \mathrm{~kg}^{-1}$ ${ }^{\circ} \mathrm{C}^{-1}$ is the specific heat of the water. This gives a potential temperature increase of about $0.0007^{\circ} \mathrm{C} \mathrm{yr}^{-1}$ (see Timmermans et al. 2003), or about $0.0005^{\circ} \mathrm{C}$ during the recording of the deep TR-1050-too small to be detectable. Although gradual changes are negligible, temperature fluctuations are observed.

The temperature time series from the shallow (2391 m) TR-1050 unit shows fluctuations with peak-to-peak amplitude of about $0.002^{\circ} \mathrm{C}$ (recall that the noise level is $\pm 0.0001^{\circ} \mathrm{C}$ ). Enhanced energy levels are clearly visible in the frequency spectra (Fig. 5) around the semidiurnal tidal frequency $M_{2}$ and inertial frequency $f$. Note that the mean buoyancy frequency $N$ over the staircase region (between the depth of the temperature minimum and the top of the homogeneous bottom layer) is approximately $2 \times 10^{-3} \mathrm{rad} \mathrm{s}^{-1}$.

At this latitude, spectral analysis cannot resolve the tidal and inertial frequencies $\left(M_{2}=1.41 \times 10^{-4} \mathrm{rad} \mathrm{s}^{-1}\right.$ and $f=1.40 \times 10^{-4} \mathrm{rad} \mathrm{s}^{-1}$ ). Further, except perhaps 


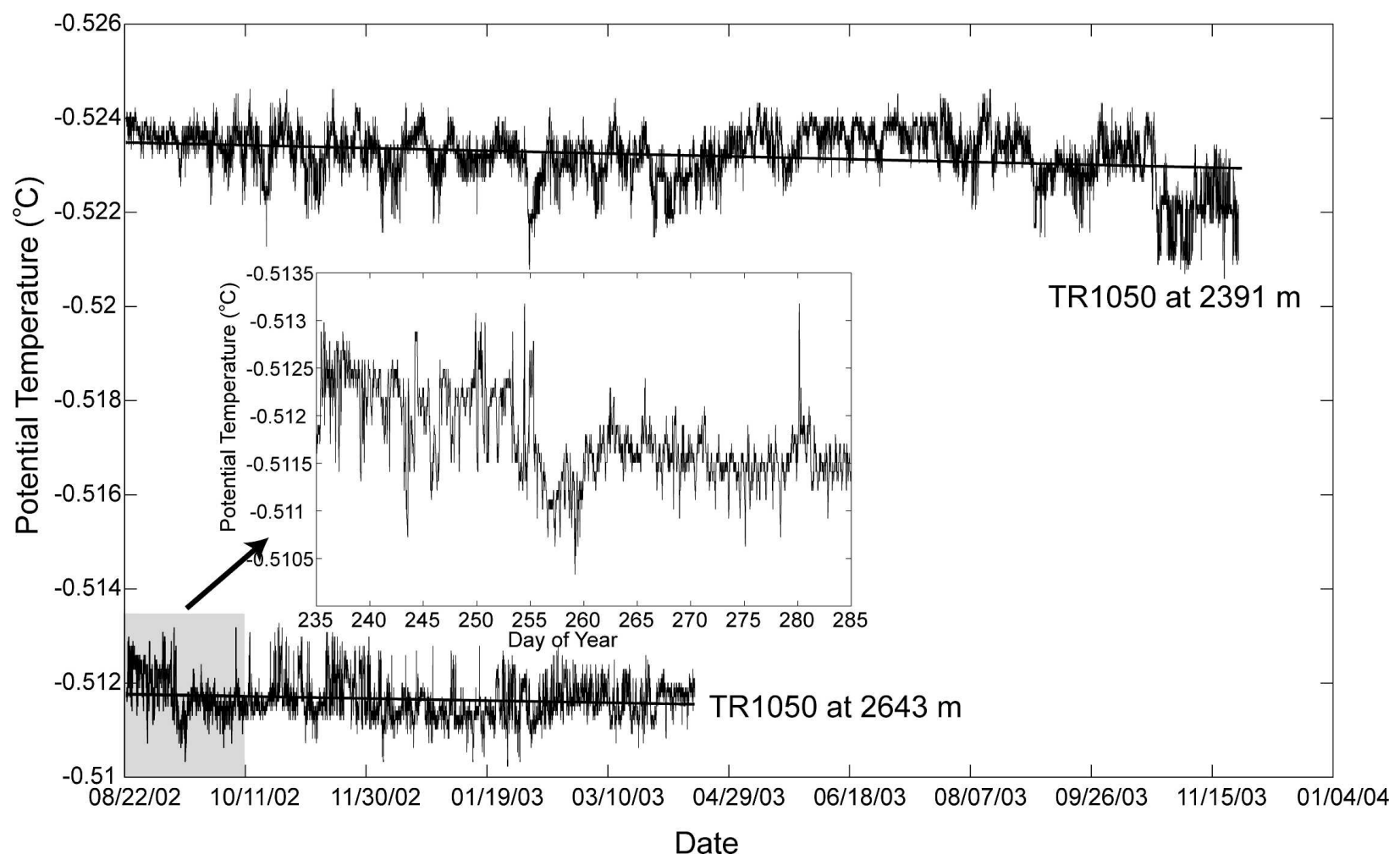

FIG. 4. TR-1050 time series of potential temperature.

very near a source, open ocean internal (tidal) waves do not show up at single harmonic frequencies but as finite frequency bands due to interactions with the varying (current and stratification) background. The spectra from the shallow TR-1050 unit suggest that there was motion of the water column or the temperature array at lower frequencies also.

The 2002 CTD profile around the depth of the shallow TR-1050 (2391 m) (Fig. 3a) shows variations of about $0.001^{\circ} \mathrm{C}$ over about $5 \mathrm{~m}$, while the temperature there is not monotonically increasing or decreasing with depth. Hence, the enhanced energy in the spectrum could be explained by a vertical motion of the water column or the instrument array near the semidiurnal frequency of about $\pm 5 \mathrm{~m}$. This vertical motion is not evident in temperature readings where there are no measurable vertical fluctuations in the CTD profile or where the vertical gradient is zero (e.g., the deeper TR1050 in the homogeneous bottom layer).

\section{b. Thermistor chain measurements}

All of the thermistors suffered pressure creep and their readings drifted with no consistent trend between thermistors. While a few of the channels seemed to be amenable to an analysis that assumes logarithmic drift (suggestive of creep under pressure) other variations were observed. The procedure found to be the best way to remove erratic behavior from the recorded temperatures while maintaining the discreet jumps in temperature between mixed layers was a filtering technique as follows (F. Johnson, RBR, Ltd., 2004, personal communication): First, a standard deviation is calculated based on the previous $n$ records, where the processing of the recorded temperatures started at $n+1$. A suitable

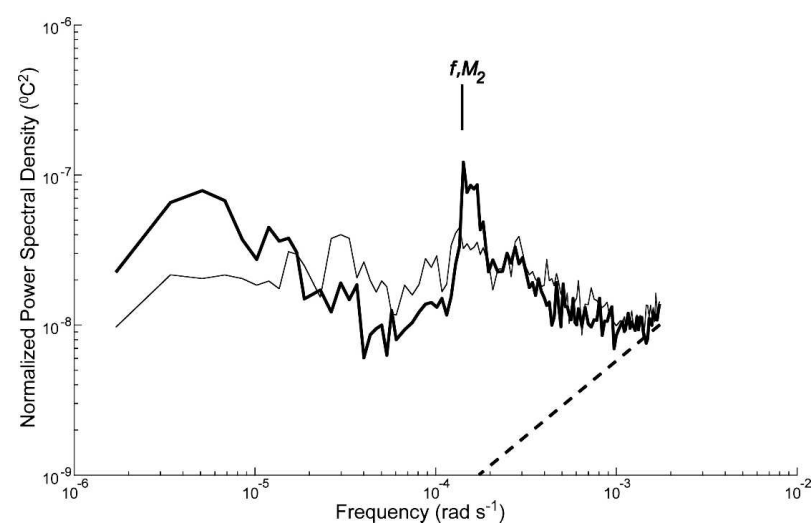

FIG. 5. TR-1050 frequency spectra at 2391 (thick line) and 2643 $\mathrm{m}$. The dashed line indicates the noise floor of the instrument. 


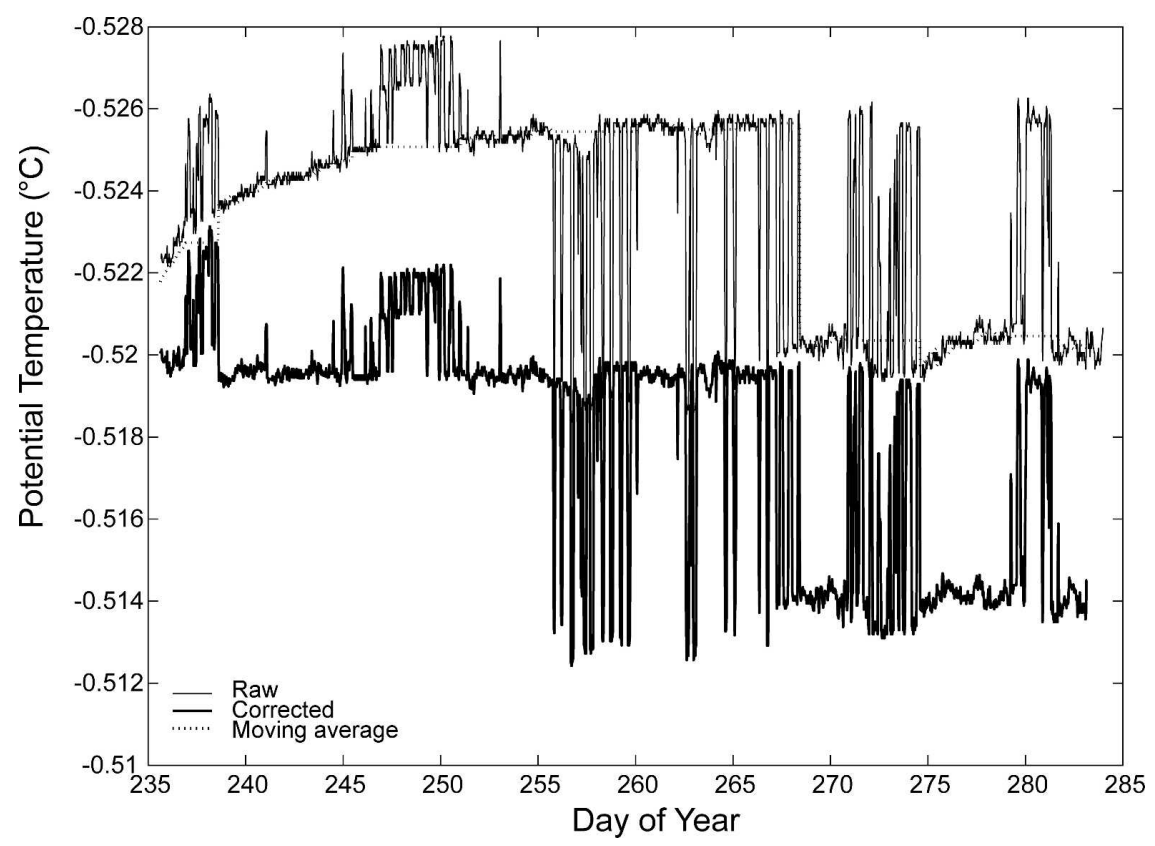

FIG. 6. Time series of thermistor 10, illustrating thermistor data processing.

value of $n$ was chosen to be 40 records, based on the minimum length of time a thermistor was located in a given step. If the standard deviation was found to be below a threshold specified such that a discrete jump could be detected $\left(0.0003^{\circ} \mathrm{C}\right)$, then an average was calculated based on the previous $n$ records to generate a moving average for the time series. If the standard deviation was above the threshold, then the existing average was maintained. This average was then compared with the previous average and if greater than a second threshold (specified to be less than the smallest discrete temperature jump, $0.001^{\circ} \mathrm{C}$ ), then it is assumed that there has been a discrete jump in the temperature (the thermistor is located in a new mixed layer), giving us an offset value. The moving average is subtracted from the raw data to flatten the data in that any long-term drift is eliminated. To obtain the final form of the output, the offset values are added to this flattened data. Last, to calibrate, the first record is subtracted from the CTD temperature upon deployment at the depth of the instrument and the difference is added to the entire record. Figure 6 provides an example. The final processed output is time series indicating discrete temperature steps. The processing also captures higher frequency fluctuations between steps, sometimes observed when a thermistor is located at the interface between two mixed layers.

Figure 7 shows the 50-day time series of potential temperature from thermistor measurements. Three well-defined steps are visible by the clusters of points.
The warmest (deepest) layer is indicated by the cluster centered around $\theta \approx-0.513^{\circ} \mathrm{C}$ (labeled 1 in Fig. 3). This layer was mostly in the depth range of thermistors 1 to 8 . The second warmest overlying step (labeled 2 in Fig. 3) is indicated by the cluster of points centered around $\theta \approx-0.519^{\circ} \mathrm{C}$, in which thermistors 9,10 , and 11 were located, and the third warmest (labeled 3 in Fig. 3) is around $\theta \approx-0.522^{\circ} \mathrm{C}$.

The two deepest mixed layers (1 and 2) are obvious for the entire record, with no apparent merging or other disruption of one of these layers. Layer 3 and mixed layers shallower are less coherent. Further, at around day 265, it would appear that either there has been a merging of layers above layer 3 , a tilting of the vertical mooring line in the water column, or a vertical excursion of one or more mixed layers.

As in the TR-1050 records, a range of temperature fluctuations are also apparent in the thermistor time series (e.g., Fig. 8). Frequency spectra are shown in Fig. 9. Thermistors that are adjacent to the largest steps in temperature (e.g., thermistors 9 and 10) show the same peaks in the frequency spectra, arguably as a result of vertical motion of the interfaces between mixed layers past the thermistors. Enhanced energy levels around the semidiurnal and inertial frequencies are apparent in the shallow chain (thermistors 9-16; Fig. 9a) measurements. Measurements from the deeper thermistors (18; Fig. 9b) show no spectral peaks since they were located for the most part in the bottom homogeneous layer where there was no temperature gradient by 


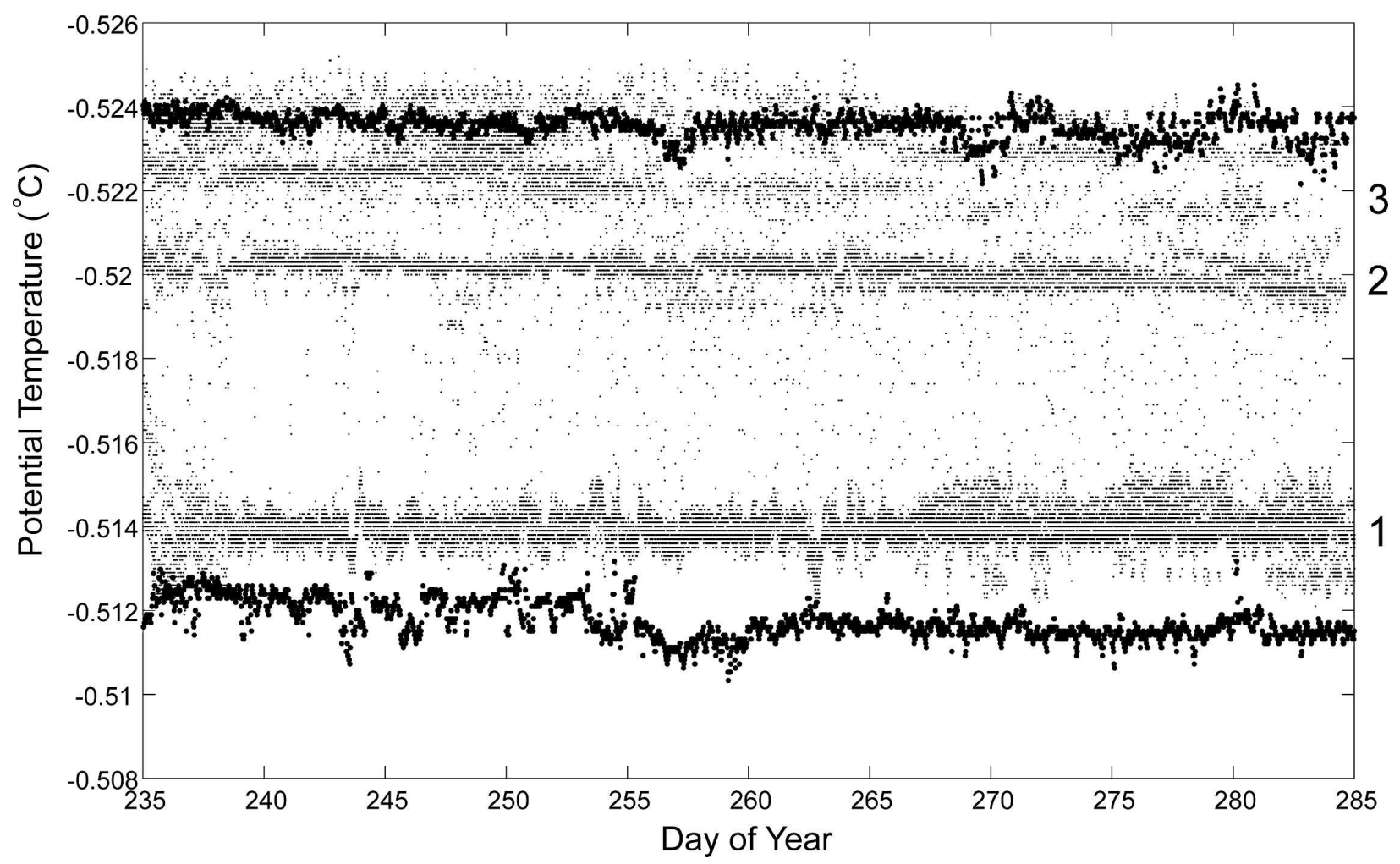

FIg. 7. Thermistor time series (22 Aug-12 Oct 2002). The lighter dots indicate measurements from thermistors 1-16, and the thick dots are TR-1050 measurements. Labels 1, 2, and 3 correspond to the well-mixed layers as shown in the potential temperature profile in Fig. 3.

which to observe vertical excursions. Because the absence of fluctuations does not necessarily imply an absence of movement, most likely the high-frequency motion is not intermittent.

\section{Dynamics}

Mooring motion does not appear to be responsible for fluctuations recorded by the array of temperature instruments. The mooring model for this particular mooring suggests that for small flows $\left(<5 \mathrm{~cm} \mathrm{~s}^{-1}\right)$ below 500-m depth, the draw down at 2500-m depth is about $12 \%$ that at the top. Based on the IPS pressure time series at about $46 \mathrm{~m}$ (Fig. 10a), this amounts to no more than $\pm 1 / 4 \mathrm{~m}$ vertical movement of the thermistor array. We note that the only unusual event as recorded by the IPS took place between 11 to 14 September 2002 (corresponding to days 255-258 of the deployment). This event, which may have been a passing eddy, tipped the top of the mooring over by about $36 \mathrm{~m}$. No anomalous events are seen in the National Centers for Environmental Prediction (NCEP) wind and sea level pressure records at the mooring site between 1 August and 13 October 2002 (Fig. 10b). From the mooring model, the 36-m descent near the surface yields a maximum vertical movement of less than $5 \mathrm{~m}$ at the middepth of the array of temperature instruments. Hence, we conclude that temperature fluctuations result from motion of the water column past the stationary instrument array.

\section{a. Vertical motion}

The temperature time series (Figs. 7 and 8) show variations where the temperature recorded by a given thermistor jumps from one mixed layer to another. Assuming that these changes in temperature arise from vertical advection of the water column (we will discuss horizontal advection in the next section), the vertical motion of the staircase structure can be inferred by matching the CTD profile of potential temperature $\theta(z)$ (Fig. 3) to the time series measurements (Fig. 11). At each time, the vertical displacement $\eta$ is obtained from the best match (in the least squares fit sense) between the thermistor data and displaced CTD profile $[\theta(z+\eta)]$.

Although this technique has obvious limitations, it enables us to estimate the staircase heave over a wide range of frequencies. Motions with a period of 12-h 


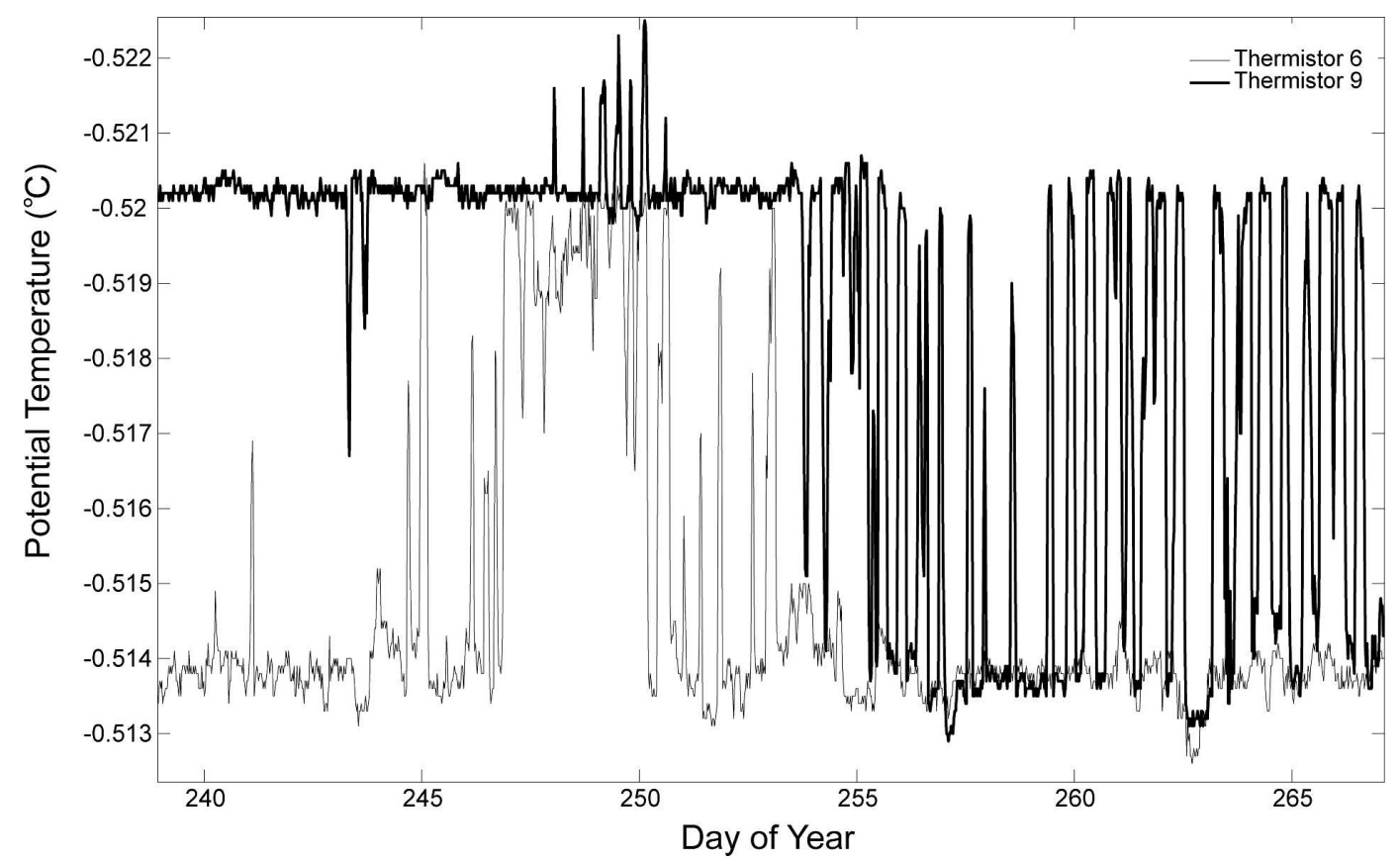

FIG. 8. Thermistor time series of potential temperature $\left({ }^{\circ} \mathrm{C}\right)$.

(frequency near $f, M_{2}$ ) are observed to have typical vertical excursions of $10-20 \mathrm{~m}$. These motions are also evident from the peaks near $f$ and $M_{2}$ in the frequency spectra (Fig. 9). Even taken conservatively, such estimates of the vertical displacements are not consistent with traditional near-inertial waves propagating down from the ice-covered ocean. Downward-propagating near-inertial internal waves in the Canada Basin are typically observed to have an rms horizontal velocity of $1-2 \mathrm{~cm} \mathrm{~s}^{-1}$, with a vertical wavelength of $20-50 \mathrm{~m}$ (Halle and Pinkel 2003; Pinkel 2005). Extrapolating this near-surface downward flux (measured where the buoyancy frequency is roughly 6 times the average value over the staircase) assuming a slowly-varying background relative to the vertical scales of the waves (Wentzel-Kramers-Brillouin approximation), the vertical displacements at depth would be at most 1-2 m, even considering frequencies up to several times $f$. However, as noted by Gerkema and Shrira (2005), there are several instances where large near-inertial vertical velocities and displacements can be expected when taking into account the horizontal component of the earth's rotation, traditionally neglected. This is particularly true for regions of small buoyancy frequency $N$. For example, van Haren and Millot (2005) measured near-inertial vertical velocities on the order of $1 / 10-1$ times the horizontal velocity in a deep homogeneous layer in the western Mediterranean Sea. We emphasize that the dynamics and the impact of near-inertial waves generated near the surface and propagating into a staircase region, as here in the Canada Basin, in the Mediterranean Sea (van Haren and Millot 2005), or in the western tropical Atlantic Ocean (Schmitt et al. 2005) are not well understood.

In addition to motion in the internal-wave frequency band, Fig. 11 indicates temperature fluctuations during the 50-day record corresponding, if strictly due to vertical advection of the staircase structure (mixed layers and interfaces), to excursions on the order of tens of meters over several days. For example, between yeardays 244 and 250, the structure deepens by about $20 \mathrm{~m}$. In the following 6 days, to day 256, the structure shallows by about $40 \mathrm{~m}$. The overall trend from about day 256 to the end of the record is a shallowing of the structure, with dips such as that around day 278 when the structure deepens by about $30 \mathrm{~m}$ to day 280 and again shallows by this much over the next two days. The CTD profiles of potential temperature at the mooring site in 2002 and 2003 indicate a staircase structure that is about 40-m shallower in 2003 than in 2002 (Fig. 12). The $0.0017^{\circ} \mathrm{C}$ offset in temperature between the two profiles may be real, implying horizontal advection (section 3b), although the difference is within accuracy limitations.

Last, note that the subinertial variation in layer depths displayed in Fig. 11 is broadly congruent with that of sea level pressure (Fig. 10b). For example, the $30-\mathrm{m}$ descent of layers during days $278-280$ is coinci- 
(a)

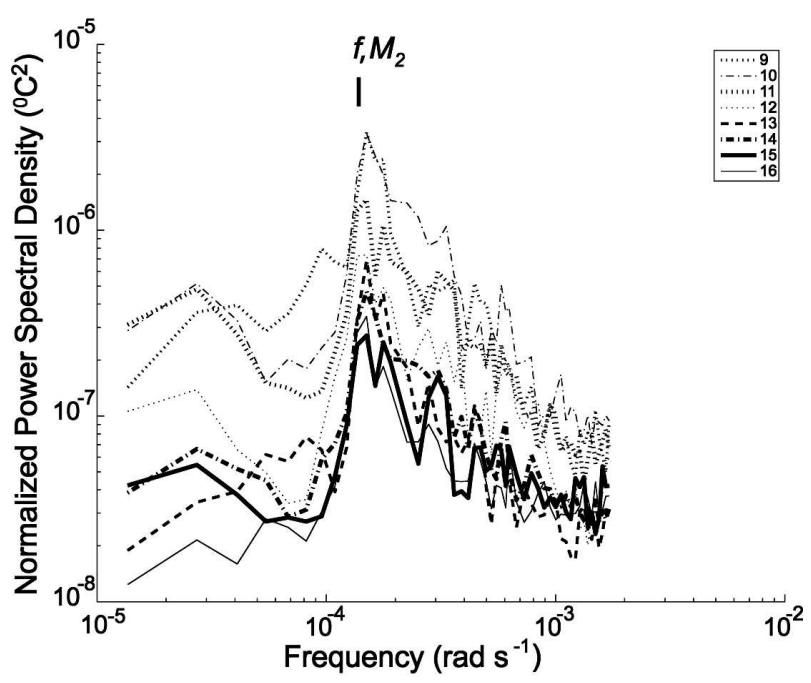

(b)

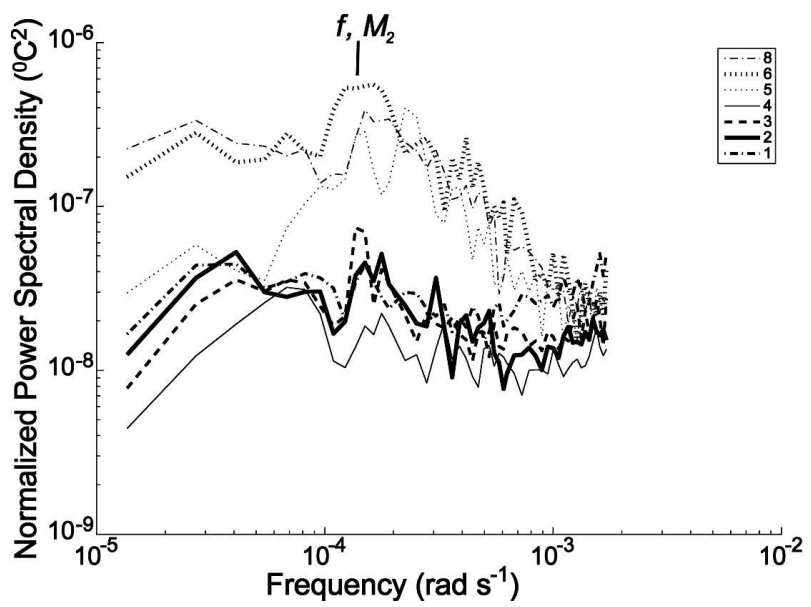

FIG. 9. Frequency spectra of thermistor (top) 9-16 and (bottom) 1-8 temperature time series.

dent with a 0.3-dbar drop in air pressure and a pronounced deepening event at day 250 also occurs in association with an atmospheric low. However, the dynamical linkage is unclear; the inverse barometric mechanism can generate a rapid adjustment of sea level, but such is $180^{\circ}$ out of phase with air-pressure variation for deep waters and small ( 0.3 dbar is equivalent to $0.3 \mathrm{~m}$ in water depth, or $1 \%$ of the deep-water signal observed here). Surprisingly, the drop in sea level pressure at day 280 was clearly measured at $46-\mathrm{m}$ depth (Fig. 10 a), suggesting no compensation of this event by the inverse barometric mechanism. In contrast, comparable changes in sea level pressure during days 260-264 (increase) and during 266-270 (decrease) were not manifest at 46-m depth. It seems these signals cannot be (a)

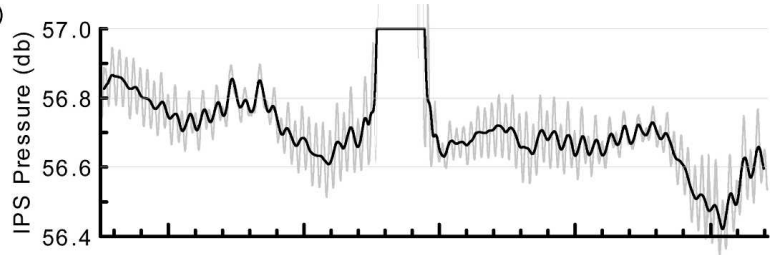

(b)

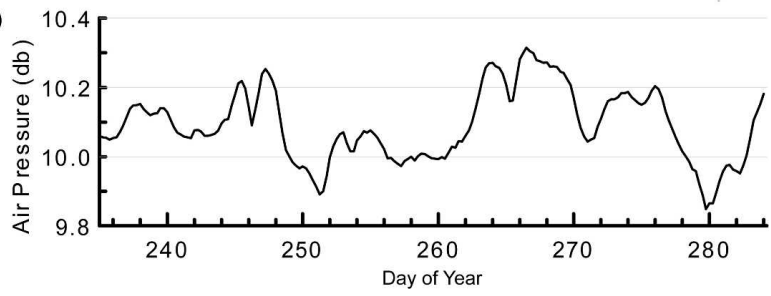

FIG. 10. (a) Hydrostatic pressure measured by the IPS positioned at a depth of about $46 \mathrm{~m}$ on the mooring. The gray line displays measurements at 1-min intervals and the black line is the running average over the $M_{2}$ tidal cycle (745 data points). The truncated positive pressure excursion (days 255-258) marks pulldown of the IPS to 82-m depth by a passing eddy. (b) Sea level pressure at the mooring site derived from NCEP reanalysis.

interpreted in the one-dimensional framework offered by the present data.

From Fig. 11, it seems reasonable to assume that vertical movement of the staircase unit is uniform across the mooring array, and vertical velocities can be inferred from the time lag for adjacent thermistors to lie in a given mixed layer. For example, Fig. 13 shows an approximately 5 -h window of the thermistor time series where the thermistors shown are from deepest to shallowest: $5,6,8,9,10$, and 11 . At 250.1 days, there is a shallowing of the structure such that the interface be-

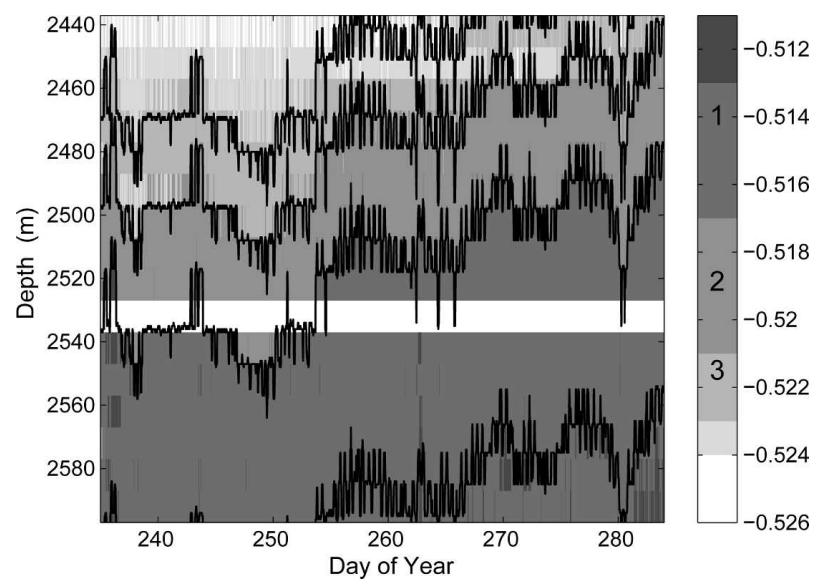

FIG. 11. Depth-time map of potential temperature from the thermistors, with color scale chosen to match the homogeneous layers. The depths of the interfaces inferred by matching the vertically displaced 2002 CTD profile of potential temperature to the measurements are plotted in black. 


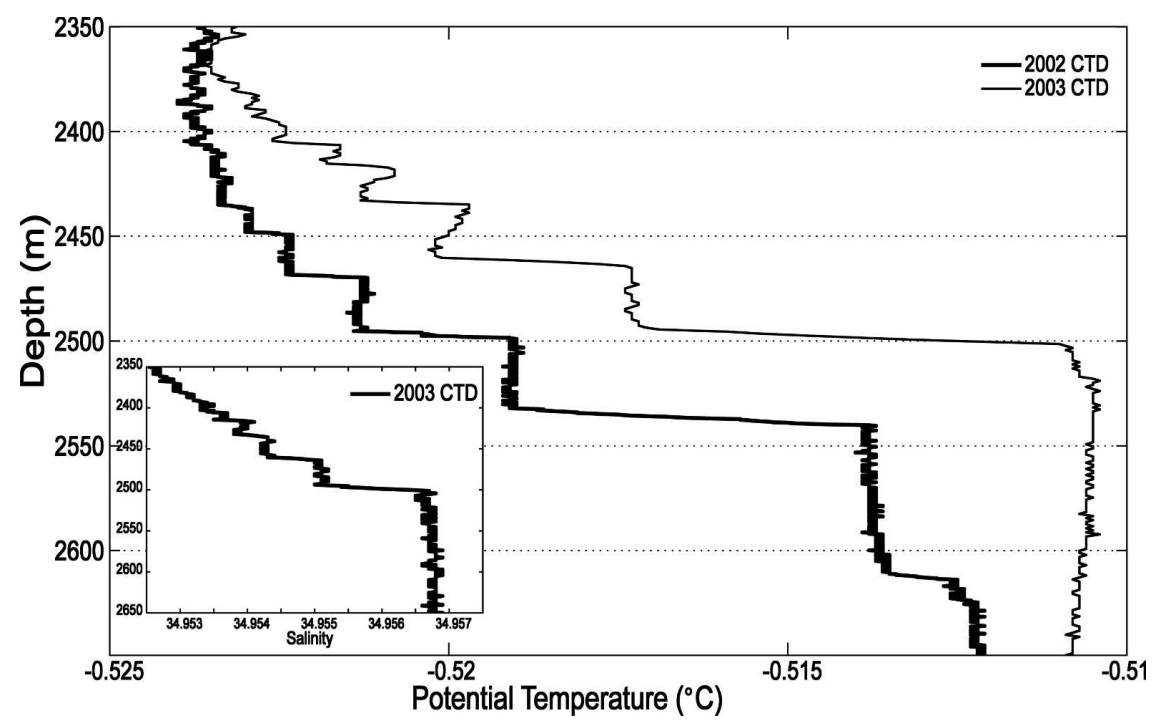

FIG. 12. CTD profiles of potential temperature at the mooring site from Louis $S$. St-Laurent expeditions in 2002 and 2003. The inset shows the 2003 salinity profile.

tween layers 1 and 2 (as labeled in Fig. 3 and in the inset of Fig. 13) moves past thermistor 5 and layer 1 is now located near the depth of thermistor 5. About $1.5 \mathrm{~h}$ later, the same interface moves past thermistor 6, while the interface between layers 2 and 3 rises past thermistor 9. After another $1.5 \mathrm{~h}$, the interface between layers 2 and 3 rises past thermistor 10. Mixed-layer 2 remains within the depth range of thermistor 8 throughout the excursion. The vertical velocity of the staircase structure is about $0.2 \mathrm{~cm} \mathrm{~s}^{-1}$ in the example presented in Fig. 13. We note that there was nothing unusual in the IPS pressure record around yearday 250 . Other examples in the thermistor time series show similar time lags and thus vertical velocities of the same order.

Basin seiching (a free oscillation of the water column that is triggered by a passing atmospheric disturbance) can be ruled out as a possible source for the subinertial vertical excursions. Below the depth of the AlphaMendeleyeev Ridge Complex $(>\sim 2400 \mathrm{~m})$ the low density contrasts yield a seiche period on the order of hundreds of days-much longer than the excursions seen in the temperature measurements. A simple calculation indicates that we would have to invoke the high density contrasts of the entire basin to obtain a theoretical period of an internal seiche in the Canada Basin that is sufficiently short to agree with the period of vertical excursions as seen in the thermistor chain measurements. For example, consider a two-layer Canada Basin, with an upper layer from the surface to the main pycnocline. The upper layer is an approximation to the Arctic Surface Water having potential density $1025 \mathrm{~kg} \mathrm{~m}^{-3}$, and the lower-layer potential density can be approximated as $1028 \mathrm{~kg} \mathrm{~m}^{-3}$. If a long-wave seiche propagates along the interface between the two layers, the motion would extend to the seabed. For an upper-layer thickness of $h=300 \mathrm{~m}$, and taking the lower layer to be much deeper, we find the natural period of an open-end rectangular basin to be

$$
T=\frac{4 L}{\sqrt{g^{\prime} h}} \approx 15 \text { days, }
$$

where $L \approx 1000 \mathrm{~km}$, the length of the Canada Basin. A higher-mode seiche (say $n=2$ ) yields $T_{2}=15 / n=7.5$ days. From the excursions seen in the thermistor measurements, it is possible that a seiche period could be 13 to 14 days. However, even a seiche with an amplitude of tens of meters in the main Arctic pycnocline would create vertical displacements of only a few centimeters around the depth of the thermistor chain. Hence, basinscale seiches would not generate vertical motions consistent with observations, and the subinertial temperature fluctuations measured at the mooring site are likely due primarily to horizontal advection.

\section{b. Horizontal advection}

CTD observations indicate that the depth of the top of the homogeneous bottom layer varies by about 100 m over $100 \mathrm{~km}$ (see Fig. 2). Thus horizontal advection may cause upheaval at the mooring site. However, we can again rule out basin seiching as a mechanism. A seiche in the main pycnocline that induces a horizontal velocity of about $0.1 \mathrm{~m} \mathrm{~s}^{-1}$ (corresponding to $10-\mathrm{m}$ amplitude) in the upper 300-m-thick layer would result in 


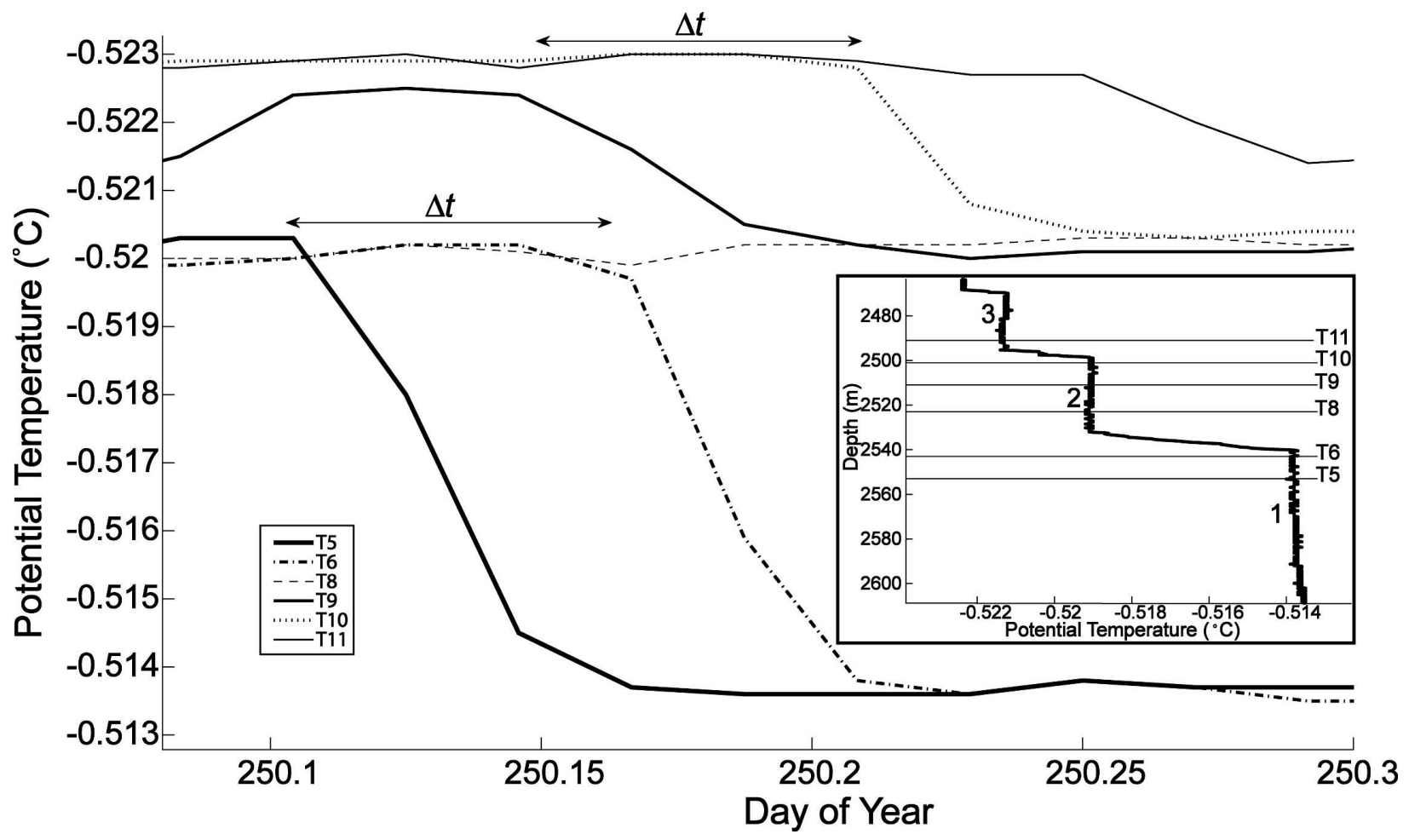

FIG. 13. Thermistor time series indicating a vertical excursion of the staircase structure by about $25 \mathrm{~m}$ over about $5 \mathrm{~h}(0.2 \mathrm{days})$. The inset shows the 2002 CTD profile.

about $0.01 \mathrm{~m} \mathrm{~s}^{-1}$ horizontal flow at the depth of the thermistor chain (in the lower layer). This corresponds to about 4-km lateral motion in one seiche period, which (based on horizontal gradients in staircase depth) would result in heaving less than $4 \mathrm{~m}$, much less than the observed 20-40 m.

Horizontal advection in the form of lateral density intrusions from boundary regions could result in vertical excursions of the staircase structure due to changes in the volume of underlying water. Consider, for example, the increase in temperature as recorded by the TR-1050 at $2643 \mathrm{~m}$ (in the homogeneous bottom layer) in the middle of September (around yeardays 255-260; see the inset Fig. 4). It seems the source of this anomalously warm water (warmer by about $0.0015^{\circ} \mathrm{C}$ ) can only be from horizontal advection, as no water with a potential temperature warmer than $-0.5119^{\circ} \mathrm{C}$ can be found below $2000 \mathrm{~m}$ at the site at the time of the deployment (Fig. 3). If this is due to a lateral intrusion, such a temperature increase would be compensated by a salinity increase of about 0.0002 (i.e., $\alpha \delta \theta=\beta \delta S$, where $\alpha=1.2 \times 10^{-4 \circ} \mathrm{C}^{-1}$ and $\left.\beta=7.6 \times 10^{-4}\right)$. Note that the potential temperature of the bottom layer of the Canada Basin generally increases toward the boundaries (Fig. 2). Based on lateral temperature and salinity gradients in the vicinity of the mooring from the
2002 CTD data at 2643 m (see Fig. 2), a warm salty intrusion coherent over $60 \mathrm{~km}$, or even less, could explain the anomalously warm water in the measurements. It is conceivable that such an intrusion could induce shallowing of the staircase structure. Again, however, we are limited by the relatively short time series and one-dimensional measurements.

Lateral intrusions can also be seen in the 2003 CTD profile at the mooring site (Fig. 12). The shallower layers of the staircase have nonuniform temperature. From the salinity profile (see the inset Fig. 12), these appear to be density compensated intrusions, although the salinity resolution is not sufficient to be conclusive. Note that between about 2400 and $2600 \mathrm{~m}$ the densities of the Canada Basin and the adjacent Makarov Basin are similar (Timmermans and Garrett 2006), with the Makarov Basin water being slightly cooler and fresher. Therefore water from the adjacent basin provides a possible source for the intrusions. While the intrusions are further evidence of lateral processes, it is unclear whether these are associated in any way to the subinertial excursions.

\section{Summary}

The temperature array revealed significant vertical movements of the staircase structure, and showed evi- 
dence of horizontal advection as well, proving the deep Canada Basin to be a more active environment than previously suspected. Enhanced energy levels around $f$ and $M_{2}$ show up in the frequency spectra of the temperature time series. Ruling out mooring motion, and assuming that the water column moves as a unit, typical vertical excursions with frequency near $f, M_{2}$ are 10$20 \mathrm{~m}$. A possible explanation could be the generation of large near-inertial displacements that can be expected in regions of very weak stratification. Larger excursions of more than $40 \mathrm{~m}$ over several days are also evident. The temperature time series suggest evidence for horizontal intrusions of new water masses, which may induce the observed subinertial motion.

How common are these large excursions of the water column? Is there a seasonal variability to the surprisingly large vertical near-inertial motion? Is the subinertial motion periodic? How valid is our assumption that the staircase moves as a unit? Does merging, splitting or other disruption of the layers occur, and if so, what is the time scale for reformation? Longer time series measurements resolving the evolution of the thickness, horizontal coherence, as well as the variability of the deep staircase structure of the Canada Basin are needed. From mooring deployments in the Canada Basin during the International Polar Year (2007-08), we aim to measure the flow field directly in at least two sites in the deep basin, enabling us to understand better the variability in the deep Canada Basin and how it could relate to upper-ocean and atmospheric processes.

Acknowledgments. Thanks are given to Frank Johnson (RBR, Ltd.) for development of the thermistor chain and advice with postdeployment processing and to Chris Garrett for valuable discussions and suggestions. Special thanks also are given to Helen
Johnson, Richard Dewey, Fiona McLaughlin, Eddy Carmack, Doug Sieberg, Sarah Zimmerman, and the captain and crew of the CCGS Louis S. St-Laurent. CTD data used here were collected on the 2002 and 2003 Arctic expeditions aboard the CCGS Louis S. St-Laurent (supported by the Fisheries and Oceans Canada Strategic Science Fund, Institute of Ocean Sciences). The PITSA mooring was funded by Environment Canada through the Climate Change Action Fund initiative in Cryospheric Monitoring for Canada. The support of the U.S. Office of Naval Research, the Natural Sciences and Engineering Research Council, Canada, and the Doherty Foundation is also gratefully acknowledged. The NCEP reanalysis data were provided by the Climate Diagnostics Center of the U.S. National Oceanic and Atmospheric Administration.

\section{REFERENCES}

Gerkema, T., and V. I. Shrira, 2005: Near inertial waves in the ocean: Beyond the "traditional approximation." J. Fluid Mech., 529, 195-219.

Halle, C., and R. Pinkel, 2003: Internal wave variability in the Beaufort Sea during the winter of 1993/1994. J. Geophys. Res., 108, 3210, doi:10.1029/2000JC000703.

Pinkel, R., 2005: Near-inertial wave propagation in the western Arctic. J. Phys. Oceanogr., 35, 645-665.

Schmitt, R. W., J. R. Ledwell, E. T. Montgomery, K. L. Polzin, and J. M. Toole, 2005: Enhanced diapycnal mixing by salt fingers in the thermocline of the tropical Atlantic. Science, 308, 685-688.

Timmermans, M.-L. E., and C. Garrett, 2006: Evolution of the deep water in the Canadian Basin in the Arctic Ocean. J. Phys. Oceanogr., 36, 866-874.

,-- , and E. Carmack, 2003: The thermohaline structure and evolution of the deep waters in the Canada Basin, Arctic Ocean. Deep-Sea Res. I, 50, 1305-1321.

van Haren, H., and C. Millot, 2005: Gyroscopic waves in the Mediterranean Sea. Geophys. Res. Lett., 32, L24614, doi:10.1029/ 2005GL023915. 